\title{
OBESITY, SMOKING STATUS AND THEIR RELATIONSHIPS IN SELECTED POPULATION GROUPS
}

\author{
Petra Lenártovál, Martina Gažarovál, Jana Mrázovál, Jana Kopčekovál, \\ Marta Habánovál, Peter Chlebo ${ }^{l}$,Kristina Jančichovál
}

'Slovak University of Agriculture in Nitra, Faculty of Agrobiology and Food Resources, Department of Human Nutrition, Nitra, Slovakia

\begin{abstract}
Background. Overweight and obesity are defined as abnormal or excessive fat accumulation that may impair health. Obesity is associated with many chronic diseases, including cardiovascular disease and diabetes, and recently the role of overweight and obesity in lung disease has received new interest. Chronic obstructive lung disease is the third-leading cause of death globally, and both obesity and diet appear to play roles in its pathophysiology. Cross-sectional studies have demonstrated an inverse association between obesity and the prevalence of chronic obstructive pulmonary disease (COPD).

Objective. This study aims to evaluate the relationship between smoking, lipid profile and obesity (body composition changes) in a selected groups of population (30 non-smokers, 30 smokers and 60 COPD patients).

Material and Methods. We evaluated fat mass, fat free mass, body mass index and lipid profile in a group of 120 randomly selected probands (60 COPD patients; 30 smokers without COPD; 30 non-smokers without COPD) to identify possible negative relationships of smoking to body composition. To the measurement of fat mass (FM) and fat free mass (FFM) was used a device Bodystat Quadscan 4000 (Bodystat Ltd, British Isles). The device works by using four-frequency bioelectrical impedance analysis. Laboratory parameters as total cholesterol (T-C), high-density cholesterol (HDL-C), low-density cholesterol (LDL-C) and triacylglycerols (TG) were investigated by automated clinical chemistry analyzer LISA 200th. The measured values were statistically processed and evaluated in a statistical program STATISTICA Cz. Version 7.1. (Kruskall-Wallis test).

Results. A comparison of the mean fat mass we found statistically highly significant differences between the group of COPD patients and non-smokers $(P<0.001)$ and insignificant differences $(P \geq 0.05)$ between the other groups of our experiment. A comparison of the mean fat mass values of all three groups of the experiment shows a steady increase in fat from non-smokers $(17.66 \pm 10.04 \mathrm{~kg})$ to COPD patients with the highest mean value $(25.08 \pm 10.14 \mathrm{~kg})$. In the group of COPD patients we recorded the lowest average value of FFM $(51.76 \pm 13.84 \mathrm{~kg})$, in group of smokers the middle $(56.06$ $\pm 10.76 \mathrm{~kg})$ and in non-smokers the highest average value of FFM $(59.91 \pm 9.90 \mathrm{~kg})$ at relatively the same body weight in the groups. Based on calculated body mass index (BMI), we found in group of COPD patients overweight in 15 cases $(25 \%)$, obesity in 7 patients $(11.67 \%)$, severe obesity in 14 patients $(23.3 \%)$ and morbid obesity in 2 patients $(3.33 \%)$; in the group of smokers overweight in 16 cases $(53.33 \%)$, obesity in 5 cases $(16.6 \%)$ and severe obesity in 1 case $(3.33 \%)$; in non-smokers we recording overweight in 14 cases (46.67\%), obesity in 5 cases (16.67\%) and severe obesity in 2 cases (6.67\%). In the lipid profile of the monitored groups of probands, we observed statistically significant differences only for LDL cholesterol (LDL-C). There was a statistically significant difference $(\mathrm{P}<0.001)$ between the group with COPD and smokers, as well as between the group of smokers and non-smokers $(\mathrm{P}<0.05)$.

Conclusions. In the vast majority of patients with COPD, the lung damage that leads to COPD is caused by long-term cigarette smoking. The presence and absence of risk factors such as smoking, inappropriate lipid profile and obesity (amount of fat mass) in selected population groups were observed. Additional studies to explore both the quantitative and qualitative changes in body composition with disease process of COPD are required.
\end{abstract}

Key words: obesity, cigarette smoking, non-smokers, smokers, COPD patients; lipid profile

Corresponding author: Petra Lenártová, Slovak University of Agriculture in Nitra, Faculty of Agrobiology and Food Resources, Department of Human Nutrition, Tr. A. Hlinku 2, 94976 Nitra, Slovak Republic, phone: +421 37641 4246, e-mail: petra.lenartova@ uniag.sk

(C) Copyright by the National Institute of Public Health NIH - National Research Institute 


\section{INTRODUCTION}

Overweight and obesity are defined as abnormal or excessive fat accumulation that may impair health. In 2016, more than 1.9 billion adults, 18 years and older, were overweight. Of these over 650 million were obese. The worldwide prevalence of obesity nearly tripled between 1975 and 2016 [31]. The proportion of obesity among the adult Slovak population was in 2016 for both men and women $25.4 \%$ [30]. The global increase in the prevalence and incidence of obesity has called serious attention to this issue as a major public health concern. Obesity is associated with many chronic diseases, including cardiovascular disease and diabetes, and recently the role of overweight and obesity in lung disease has received new interest [15].

Chronic obstructive pulmonary disease (COPD) is another condition that is associated with severe morbidity and mortality globally [8, 21, 22, 24]. Chronic obstructive lung disease is the third-leading cause of death globally, and both obesity and diet appear to play roles in its pathophysiology [13, 15]. COPD is characterized by airflow obstruction, and is the umbrella term for two conditions: chronic bronchitis and emphysema, both of which are related to similar etiology and may coexist. Lung function, which is readily measured by spirometry, is the defining feature of COPD [21]. Cigarette smoking is the most commonly encountered and readily identifiable risk factor for COPD [7].

Cigarette smoke contains $\approx 4,700$ chemical constituents and can increase production of endogenous reactive oxygen species in target cell populations [27, 28]. However, it is not clear which quantitative factors related to smoking influence the prognosis of COPD patients [1].

Cross-sectional studies have demonstrated an inverse association between obesity and the prevalence of COPD [11]. It is possible that improper lung function increases the risk of developing obesity. This may be due to the following three causes: (1) COPD patients' difficulty breathing while exercising often results in lower levels of physical activity and thus fewer calories burned in exercise, (2) a common side effect of long-term glucocorticosteroid medications is weight gain and (3) due to being hypoxemic both at rest and with exercise, COPD patients are unable to utilize oxygen for the breakdown of fatty acids through beta oxidation $[11,20]$. Although the association between obesity and COPD is increasingly recognized, the mechanisms involved and the nature of the relationship are still unclear. One reason for this uncertainty is that studies looking at COPD typically have included current smokers or those with a history of smoking [5]. Since smoking is the number one risk factor for the development of COPD [10], including smokers in the studies makes it more difficult to investigate whether obesity is playing an independent role in the development of COPD, aside from the smoking, and whether obesity is associated with a dose-response relationship [12].

COPD is considered as a systemic disease according to much concomitant comorbidity in patients. These comorbidities significantly impact on patient outcomes. Evidence for this approach has been provided by strong associations with increased rates especially with cardiovascular diseases, metabolic syndrome, anaemia, musculoskeletal disease and pulmonary malignancies. A number of studies have shown a high connectivity between COPD and cardiovascular morbidity and mortality and pulmonary embolism. Hypercholesterolemia probably is hugely responsible for those events [33].

The metabolic defects that ensue in obesity include increased levels of free fatty acids resulting from insulin resistance, increased LDL-cholesterol, VLDL and triglycerides and decrease in HDL-cholesterol. It is most likely that presentation of increased free fatty acids to liver as a function of obesity is primarily responsible for over production of VLDL and this is probably the key to increased LDL via the sequence: VLDL $\rightarrow$ intermediate density lipoprotein (IDL) $\rightarrow$ LDL [32].

Inflammation may also play a role in the obesityCOPD association. Obese individuals have elevated levels of a variety of inflammatory markers, including TNF-a, IL-6, and adipose resident macrophages, which results in an increased level of inflammation both locally and systemically [9].

This study aims to evaluate the relationship between smoking, lipid profile and obesity (body composition changes in COPD) in a selected groups of population (30 non-smokers, 30 smokers and 60 COPD patients).

\section{MATERIALS AND METHODS}

The study was conducted on patients with chronic obstructive pulmonary disease $(n=60)$ from Specialized St. Svorad Hospital Nitra Zobor, Slovakia, who were treated by means of hospitalization or outpatient basis. Observation group consisted of clinically stable patients acute deterioration of the patients was excluded from the reference file. The control group consisted of probands from the general population without COPD, acquired by random selection, who were divided into two subgroups: smokers $(n=30)$ and non-smokers $(n=30)$ represented individuals of both sexes.

We evaluated fat mass (FM); fat free mass (FFM); body mass index (BMI) and lipid profile in a group of 120 randomly selected probands (60 COPD patients - the cause of their COPD diagnosis was long-term 
cigarette smoking; 30 smokers without COPD; 30 non-smokers without COPD) to identify possible negative relationships of smoking to body composition (especially in relation to fat mass).

The research was approved by the ethics committee, approval number 4/071220/2020; Study Protocol Title: Long-term strategic research of prevention, intervention and mechanisms of obesity and its comorbidities. We received the signed informed consent to be included in the study and carrying out appropriate investigations from all subjects.

The examination of the functional state of the lungs of COPD patients was performed using spirometry and Bodyplethysmographic to confirm the diagnosis and determine the stage of the disease. Patients were classified into different groups according to the severity of the disease (Gold I to IV). Lung function was evaluated using spirometer @2005 ZAN® Meßgeräte, GmbH Germany.

To the body weight measure of probands we used a BRUTUS Tanita digital personal scale (Tanita Corporation, Tokyo, Japan). Body weight was determined in underwear (digital scale, accuracy of measurement: $0.1 \mathrm{~kg}$ ). To the body height measure of probands we used an ultrasonic height measuring unit BODYSON (Ultrasound Height Measuring Unit MZ10020) (ADE GmbH \& Co., Hamburg, Germany). The measuring range is $500-2500 \mathrm{~mm}$ with a division of $5 \mathrm{~mm}$. The meter is characterized by high accuracy, can be checked (spirit level) and its operation is simple. Body mass index (BMI) was calculated from body weight and body height of probands.

To the measurement of fat mass (FM) and fat free mass (FFM) was used a device Bodystat Quadscan 4000 (Bodystat Ltd, British Isles). The device works by using four-frequency bioelectrical impedance analysis (5; 50; 100 and $200 \mathrm{kHz})$. Regression equations are then derived which relate impedance to fat free mass (FFM) or total body water (TBW) measured by independent techniques. In our work, we adhered to the standard conditions of measurement: the probands were placed on the examination bed in a supine position with their lower limbs outstretched. The upper limbs are placed loosely next to the body, they must not touch the body. Two sensing electrodes with input and output cable are placed on the right hand and right foot, which ensure the supply of electrical current into the body and its feedback detection at the exit from the body and connection to the device software. The probe must not have a pacemaker or insulin pump or any electronic devices. The skin of the limbs must be at normal temperature and dry. Before starting the measurement itself, the personal data of the proband are first entered into the device: sex, age, weight, height, waist and hip circumference, current energy expenditure. This is followed by a custom measurement that takes a few seconds. Subsequently, the software of the device evaluates the given parameters.

Blood from probands was collected during hospitalization or outpatient examination. Laboratory parameters as total cholesterol (T-C), high-density cholesterol (HDL-C), low-density cholesterol (LDL-C) and triacylglycerols (TG) were investigated by automated clinical chemistry analyzer LISA $200^{\text {th }}$. The device operates at wavelengths from $350-600$ $\mathrm{nm}$, in fully automatic mode with 3-stage quality control, automatic control of cuvettes cleanliness, with automatic sample dilution. The device includes software for quality control of the results. The analyzer is working after programming fully automatically.

The measured values were statistically processed and evaluated in a statistical program STATISTICA Cz. version 7.1. To the statistically evaluate of our experiment we used the Kruskall-Wallis test.

\section{RESULTS AND DISCUSSION}

Based on the clinical stage of the disease according to GOLD (stage I. - IV.), were COPD patients $(n=60)$ in the following percentage: stage I. $-26.67 \%$; stage II. $-71.67 \%$; stage III. $-0 \%$; stage IV. $-1.66 \%$. The group of COPD patients consisted of 12 women and 48 men; the group of smokers consisted of 18 women and 12 men and the group of non-smokers consisted of 17 women and 13 men.

From the obtained individual values, we calculated the basic statistical characteristics of probands (Table 1).

Based on calculated body mass index (BMI), we found in group of COPD patients $(n=60)$ cachexia in 1 case $(1.67 \%)$, underweight in 4 cases $(6.67 \%)$, normal BMI in 17 cases $(28.33 \%)$, overweight in 15 cases $(25 \%)$, obesity in 7 patients $(11.67 \%)$, severe obesity in 14 patients $(23.3 \%)$ and morbid obesity in 2 patients $(3.33 \%)$. In the group of smokers $(n=30)$, we found underweight in 1 case $(3.33 \%)$, normal BMI in 9 cases (30\%), overweight in 16 cases $(53.33 \%)$, obesity in 5 cases $(16.6 \%)$ and severe obesity in 1 case $(3.33 \%)$. No cachexia, underweight or morbid obesity were reported in this group. In the group of non-smokers $(n=30)$ we recording normal BMI in 8 cases $(26.67 \%)$, overweight in 14 cases $(46.67 \%)$, obesity in 5 cases $(16.67 \%)$ and severe obesity in 2 cases (6.67\%). In this group were reported no cachexia, underweight or morbid obesity. The results correlate with the incidence of obesity in Slovak population. The results of our experiment showed that COPD patients have a lower body weight and a slightly higher BMI value compared to probands from the general population without COPD.

Because body mass index (BMI) does not take into account fat mass, we measured body composition using BIA in the monitored probands. 
Table 1. Basic characteristics of probands $(n=120)$

\begin{tabular}{|c|c|c|c|c|c|c|c|}
\hline \multirow{2}{*}{ Characteristic } & \multicolumn{2}{|c|}{ COPD Patients $(\mathrm{n}=60)$} & \multicolumn{2}{c|}{ Smokers $(\mathrm{n}=30)$} & \multicolumn{2}{c|}{ Non-smokers $(\mathrm{n}=30)$} & \multirow{2}{*}{$\mathrm{P}-\mathrm{Value}$} \\
\cline { 2 - 8 } & mean \pm SD & min. - max. & mean \pm SD & min. - max. & mean \pm SD & min. - max. & \\
\hline Age $(\mathrm{yrs})$ & $69.25 \pm 9.90$ & $49-87$ & $46.53 \pm 9.22$ & $26-59$ & $52 \pm 6.51$ & $32-63$ & - \\
\hline Body weight $(\mathrm{kg})$ & $76.73 \pm 20.23$ & $38.6-136.8$ & $77.83 \pm 12.76$ & $53.2-101.7$ & $77.57 \pm 16.34$ & $50-117.5$ & $\mathrm{P} \geq 0.05$ \\
\hline FM $(\mathrm{kg})$ & $25.08 \pm 10.14$ & $10.3-57.1$ & $21.77 \pm 9.06$ & $7.5-45$ & $17.66 \pm 10.04$ & $6.5-50.7$ & $\mathrm{P}<0.001$ \\
\hline FFM $(\mathrm{kg})$ & $51.76 \pm 13.84$ & $22.1-81.5$ & $56.06 \pm 10.76$ & $38.8-75.4$ & $59.91 \pm 9.90$ & $43.5-80.2$ & $\mathrm{P}<0.05$ \\
\hline BMI $\left(\mathrm{kg} . \mathrm{m}^{-2}\right)$ & $28.5 \pm 7.05$ & $15.3-46.8$ & $26.89 \pm 4.07$ & $20-36.8$ & $27.29 \pm 4.42$ & $18.6-37$ & $\mathrm{P} \geq 0.05$ \\
\hline T-C $\left(\mathrm{mmol} . \mathrm{L}^{-1}\right)$ & $4.69 \pm 1.09$ & $2.9-8.73$ & $5.01 \pm 0.94$ & $3.23-6.85$ & $5.33 \pm 1.04$ & $2.93-7.18$ & $\mathrm{P}<0.05$ \\
\hline HDL-C $\left(\mathrm{mmol} . \mathrm{L}^{-1}\right)$ & $1.43 \pm 0.55$ & $0.53-2.74$ & $1.58 \pm 0.35$ & $1.05-2.53$ & $1.89 \pm 0.27$ & $1.23-2.47$ & $\mathrm{P}<0.001$ \\
\hline LDL-C $\left(\mathrm{mmol} . L^{-1}\right)$ & $2.77 \pm 1.05$ & $0.62-6.29$ & $3.57 \pm 0.69$ & $2.38-4.67$ & $2.83 \pm 1.02$ & $0.93-4.53$ & $\mathrm{P}<0.001$ \\
\hline TG $\left(\mathrm{mmol} . \mathrm{L}^{-1}\right)$ & $1.23 \pm 0.53$ & $0.3-2.52$ & $1.34 \pm 1.6$ & $0.42-9.45$ & $1.34 \pm 0.85$ & $0.44-4.52$ & $\mathrm{P} \geq 0.05$ \\
\hline
\end{tabular}

Data are expressed as mean \pm standard deviation (SD), min. - max.; FM (fat mass); FFM (fat free mass); BMI (body mass index); T-C (total cholesterol); LDL-C (low density cholesterol); HDL-C (high density cholesterol); TG (triacylglycerols)

Bioelectrical impedance analysis (BIA) is a method for estimating body composition, in particular body fat and muscle mass, where a weak electric current flows through the body and the voltage is measured in order to calculate impedance (resistance) of the body. Most body water is stored in muscle. Therefore, if a person is more muscular there is a high chance that the person will also have more body water, which leads to lower impedance. BIA actually determines the electrical impedance, or opposition to the flow of an electric current through body tissues which can then be used to estimate total body water (TBW), which can be used to estimate fat-free body mass and, by difference with body weight, body fat [19].

The results for the parameter "fat mass" in the monitored groups of probands are follows: we found statistically highly significant differences between the group of COPD patients and non-smokers $(\mathrm{P}<0.001)$ and insignificant differences $(\mathrm{P} \geq 0.05)$ between the other groups of our experiment. A comparison of the mean fat mass values of all three groups of the experiment shows a steady increase in fat from nonsmokers $(17.66 \pm 10.04 \mathrm{~kg})$ to COPD patients with the highest mean value $(25.08 \pm 10.14 \mathrm{~kg})$ (Figure 1). This finding may be related to the negative effect of cigarette smoke in smokers and patients as well as to the development of chronic obstructive pulmonary disease in patients, as all three groups had approximately the same average body weight (about $77 \mathrm{~kg}$ - Table 1).

Although smokers did not show significant difference in mean body mass index than those who never smoked, they showed more metabolically adverse fat distributions with increasing smoking amounts [17]. This finding suggests that smoking is not beneficial for weight control. Therefore, smoking cessation and avoidance of smoking commencement should be addressed as important public health issues in preventing obesity and related complications.

Among smokers, cigarettes smoked per day were positively associated with central fat accumulation, particularly in women [6]. Substantial evidence shows that cigarette smoking induces multiple pathological effects in adipose tissue, such as differentiation of adipocytes, lipolysis, and secretion properties in adipose tissue [29].

Fat free mass (FFM) is made up of muscle and bone mass of the body. Our measurements show that in the group of COPD patients we recorded the lowest average value of FFM $(51.76 \pm 13.84 \mathrm{~kg})$, in group of smokers the middle $(56.06 \pm 10.76 \mathrm{~kg})$ and in nonsmokers the highest average value of FFM $(59.91 \pm 9.90$ $\mathrm{kg}$ ) at relatively the same body weight in the groups (about $77 \mathrm{~kg}$ - Table 1).

In patients with COPD, this is related to the gradual loss of muscle mass - which is an unfavorable prognostic indicator of their disease; in smokers lower FFM may indicate a negative effect of cigarette smoke on their metabolism and their overall physical and health status.

Smokers are exposed to the effects of oxidative stress, with its negative effects on the cardiovascular and respiratory systems. Recently, osteoporosis, diabetes mellitus and obesity have become increasingly common in patients with COPD. The above, together with the ongoing COPD, contributes to reducing the quality of life. Progressive deterioration of lung function in a smoker can be averted only by immediate cessation of smoking and the exclusion of other risk factors, as well as comprehensive treatment including pharmacological, rehabilitation treatment and nutritional intervention. The treatment of COPD must be complex and effective. The pharmacological part of the treatment should gradually improve the health condition, reduce the complications of the disease and the outbreak of exacerbations. Nonpharmacological treatment - nutritional support aims to improve physical fitness and reduce unwanted loss of muscle mass.

Subsequently, we were interested in the lipid profile in the monitored groups of probands. There was no significant difference in the T-C between the 


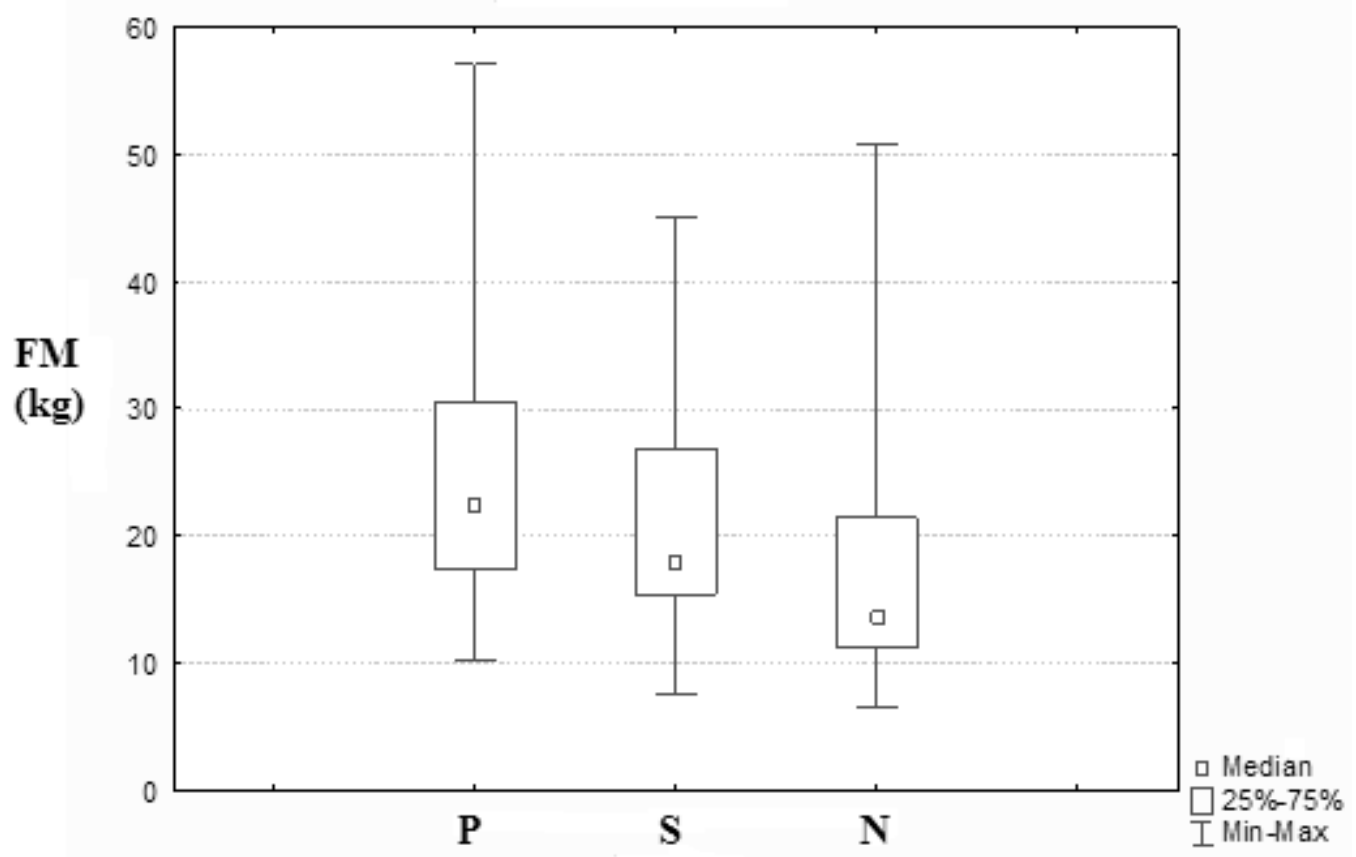

Figure 1. Evaluation of fat mass (FM) by device Bodystat Quadscan 4000 in the monitored groups: COPD patients (P), smokers $(\mathrm{S})$ and non-smokers $(\mathrm{N})(\mathrm{P}<0.001)$

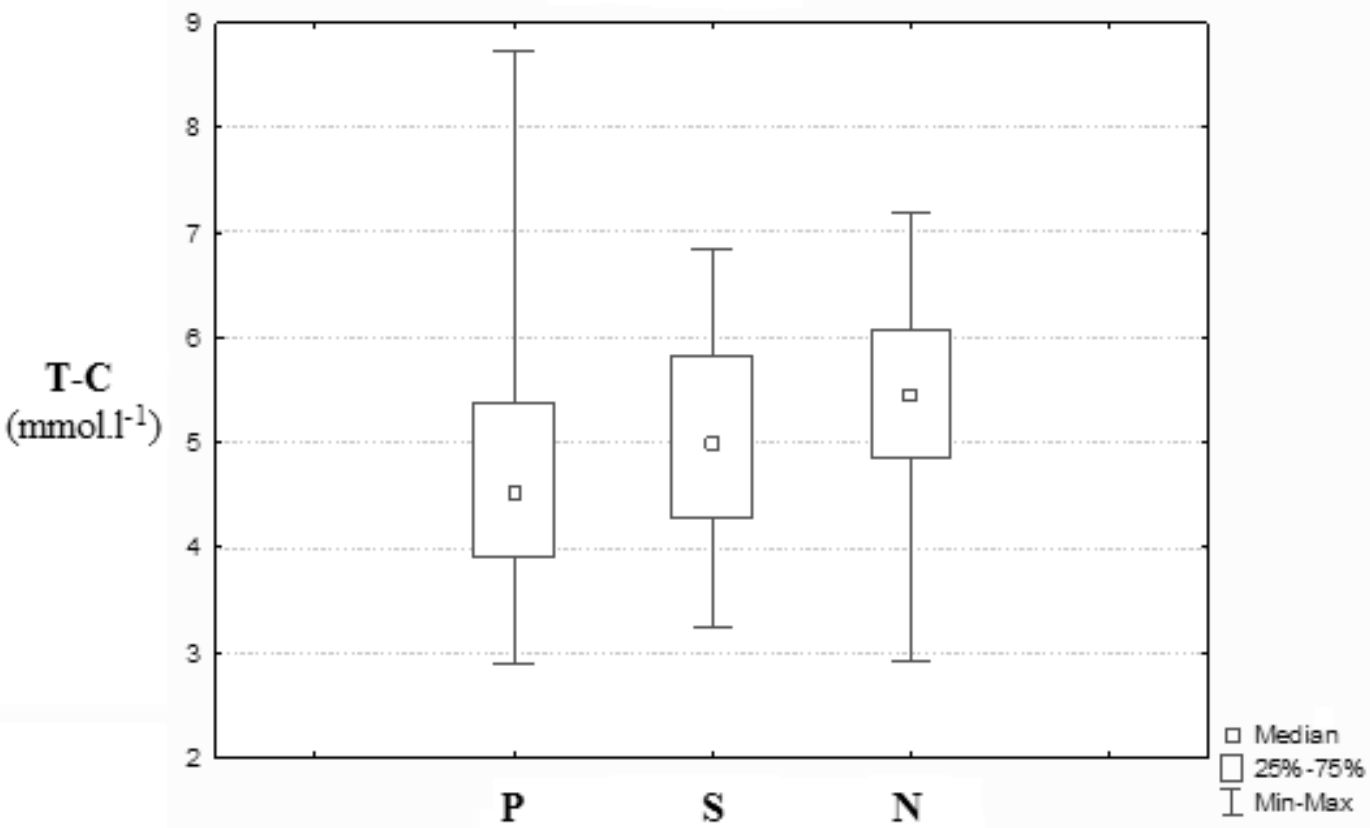

Figure 2. Levels of total cholesterol (T-C) in the monitored groups: COPD patients (P), smokers (S) and non-smokers (N) $(\mathrm{P}<0.05)$

group of patients and non-smokers, and no significant difference $(\mathrm{P} \geq 0.05)$ was found between the other groups (Figure 2).

Dyslipidemia, a major risk factor for coronary heart disease and metabolic syndrome, is characterized by a cluster of lipid abnormalities such as an elevated level of triglyceride (TG), a reduced level of HDL-C and an increased level of LDL-C. A number of studies have evaluated the relationship between COPD and blood lipid profiles with inconsistent results. While some authors reported reduced serum levels of HDL or increased serum levels of TG in COPD patients [4, 14], others did not observe any significant changes in lipid serum profiles [2].

There was a statistically significant difference $(\mathrm{P}<0.001)$ in the LDL-C level between the groups of patients and smokers, a statistically significant difference between the group of smokers and nonsmokers $(\mathrm{P}<0.05)$ The mean LDL value in the group of patients was $2.77 \pm 1.05 \mathrm{mmol}^{-1}$, in the group of smokers $3.57 \pm 0.69 \mathrm{mmol}^{-\mathrm{l}^{-1}}$ and $2.83 \pm 1.02 \mathrm{mmol}^{-\mathrm{l}^{-1}}$ in the group non-smokers (Figure 3). 


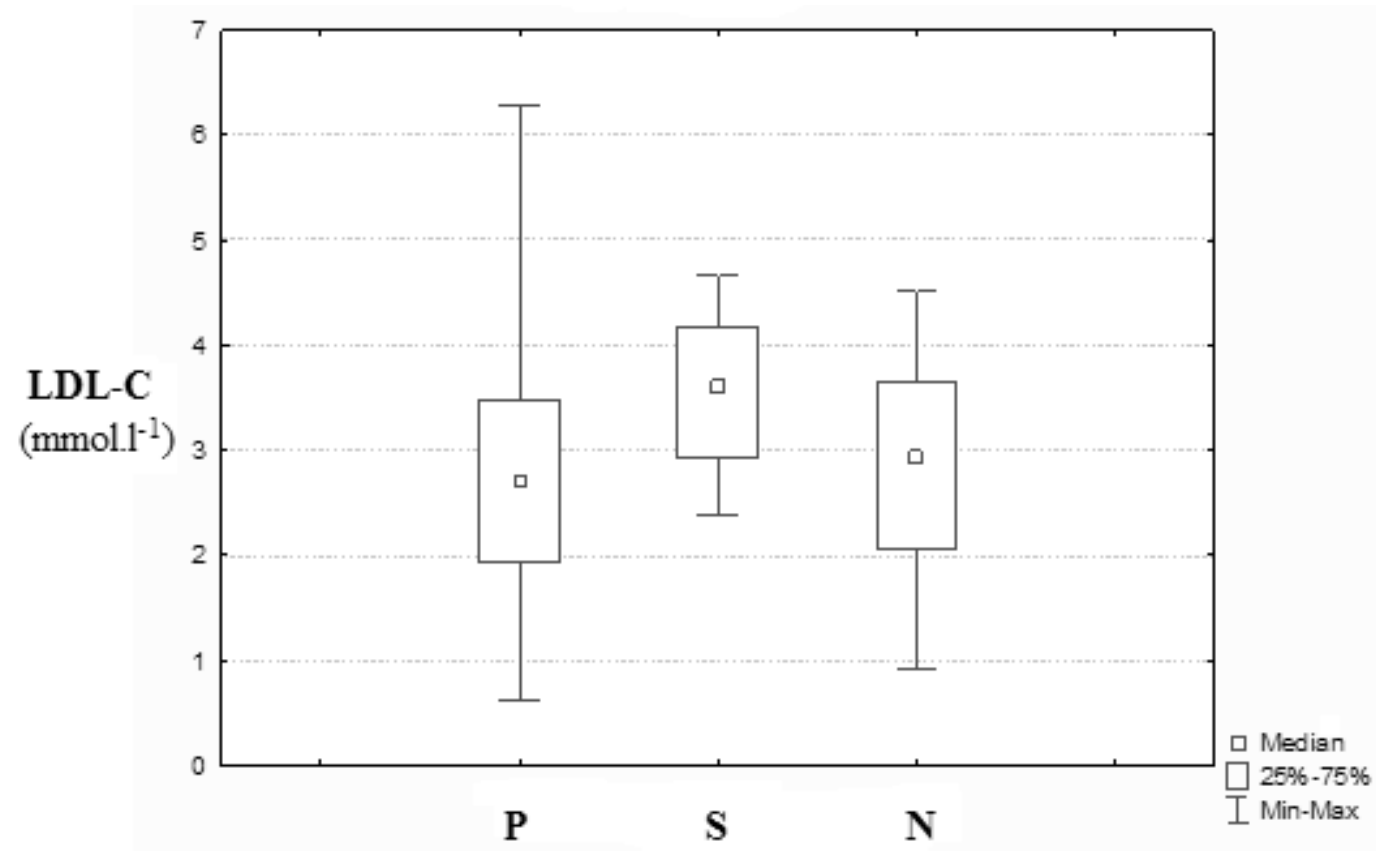

Figure 3. Levels of low density cholesterol (LDL-C) in the monitored groups : COPD patients (P), smokers (S) and nonsmokers $(\mathrm{N})(\mathrm{P}<0.001)$

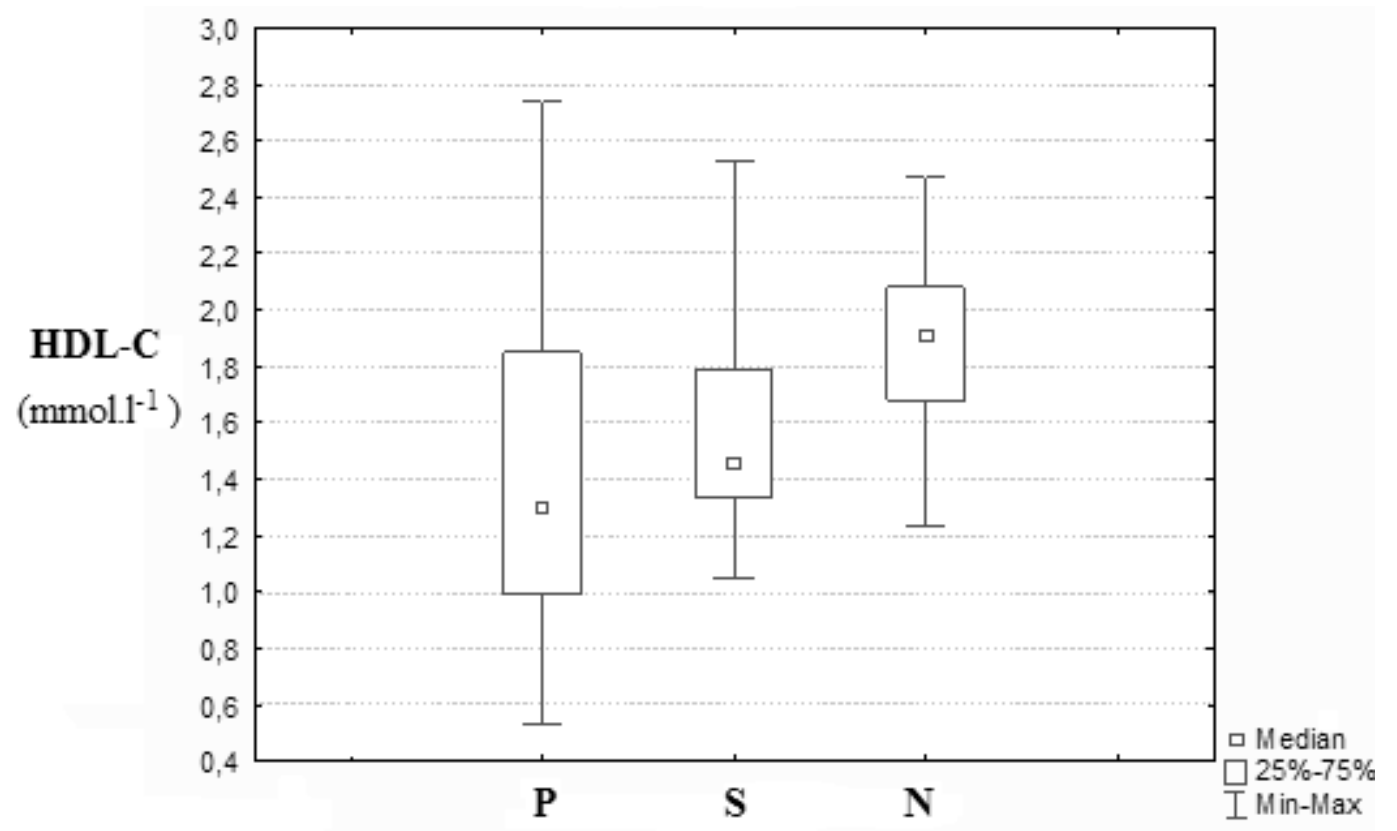

Figure 4. Levels of high density cholesterol (HDL-C) in the monitored groups : COPD patients (P), smokers (S) and nonsmokers $(\mathrm{N})(\mathrm{P}<0.001)$

Hypercholesterolemia in COPD is considered as comorbidity, one of the metabolic syndrome. According to some dates severe COPD is associated with increased levels of HDL-C, which is partially attributable to oral steroid use. HDL-C in this population is not associated with reduced risk of angiographically proven coronary artery disease [25]. We found a statistically highly significant difference $(\mathrm{P}<0.001)$ between the group of patients and smokers, a statistically significant difference between the group of smokers and non-smokers $(\mathrm{P}<0.05)$ (Figure 4).
The prevalence of metabolic syndrome (MS) is high in COPD patients and higher value of triacylglycerols (TG) was the MS component associated with higher risk of five-year mortality in COPD patients [26].

By multiple comparisons of $P$ values, we did not find significant differences between the observed groups in the observed trait $(\mathrm{P} \geq 0.05)$ (Figure 5). The lowest TG values were found in the group of COPD patients; the TG values in the group of smokers and non-smokers were approximately at the same level. This finding indicates the efficacy of treating 


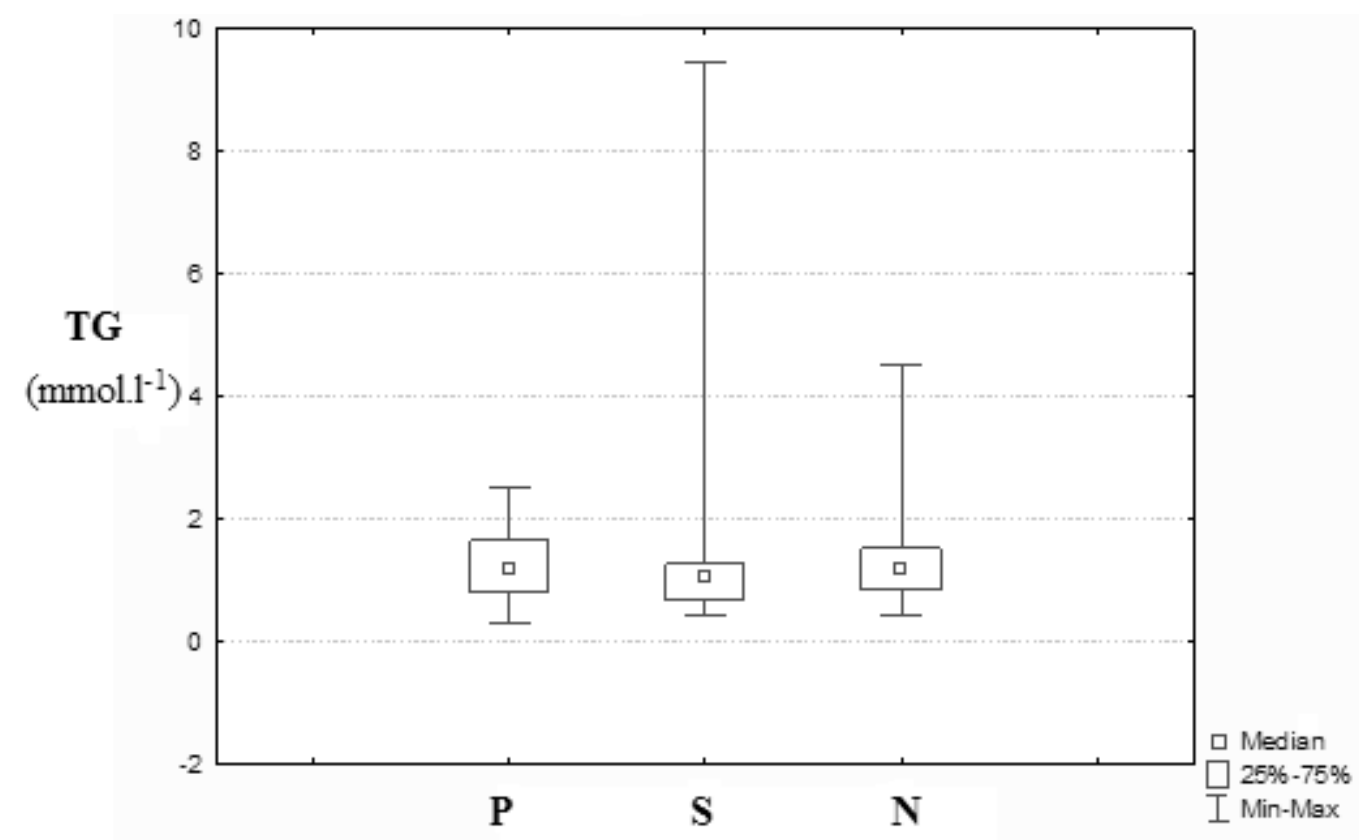

Figure 5. Levels of triacylglycerols (TG) in the monitored groups : COPD patients (P), smokers (S) and non-smokers (N) $(\mathrm{P} \geq 0.05)$

dyslipidemia in COPD patients. Patients who were not receiving treatment for dyslipidaemia showed that TG levels were higher in patients with stable COPD than in healthy individuals [34].

In COPD patients, metabolic syndrome did not additionally impact patients' functional outcomes but did impact the prevalence of co-morbidities first of all cardiovascular $[3,16]$. According to dates from some studies high level of cholesterol as a part of a metabolic syndrome in COPD patients is associated with more serious and more frequent exacerbations $[18,23]$.

\section{CONCLUSIONS}

In the vast majority of patients with COPD, the lung damage that leads to COPD is caused by long-term cigarette smoking. But there are likely other factors at play in the development of COPD, such as a genetic susceptibility to the disease, because not all smokers develop COPD. There is little data about the combined effects of COPD and obesity.

In our study, we observed the presence and absence of risk factors such as smoking, inappropriate lipid profile and obesity (amount of fat mass) in selected population groups.

In fat mass (FM) we found statistically highly significant differences between the group of COPD patients and non-smokers $(\mathrm{P}<0.001)$ and insignificant differences $(\mathrm{P} \geq 0.05)$ between the other groups of our experiment. A comparison of the mean FM values of all three groups of the experiment shows a steady increase in fat from non-smokers $(17.66 \pm 10.04 \mathrm{~kg})$ to COPD patients with the highest mean value $(25.08 \pm 10.14$ $\mathrm{kg}$ ). Fat free mass (FFM) measurements show that in the group of COPD patients we recorded the lowest average value of FFM $(51.76 \pm 13.84 \mathrm{~kg})$, in group of smokers the middle $(56.06 \pm 10.76 \mathrm{~kg})$ and in nonsmokers the highest average value of FFM (59.91 \pm 9.90 $\mathrm{kg}$ ) at relatively the same body weight in the groups. In patients with COPD, this is related to the gradual loss of muscle mass - which is an unfavorable prognostic indicator of their disease; in smokers lower FFM may indicate a negative effect of cigarette smoke on their metabolism and their overall physical and health status. In the lipid profile of the monitored groups of probands, we observed statistically significant differences only for LDL cholesterol.

Obesity and COPD are multifactorial diseases and additional studies are required to explore both the quantitative and qualitative changes in body composition with disease process of COPD.

\section{Acknowledgments}

This publication was created thanks to support under the Operational Programme Integrated Infrastructure for the project: Long-term strategic research of prevention, intervention and mechanisms of obesity and its comorbidities, IMTS: 313011 V344, co-financed by the European Regional Development Fund, cofinanced by the European Regional Development Fund and KEGA 004SPU-4/2019.

\section{Conflict of interest}

The authors declare no conflict of interest. 


\section{REFERENCES}

1. Bai J.W., Chen X., Liu S., Yu L., Xu J.F.: Smoking cessation affects the natural history of COPD Int $\mathrm{J}$ Chron Obstruct Pulmon Dis. 2017; 12: 3323-3328. doi: 10.2147/COPD.S150243.

2. Basili S, Ferroni P, Vieri M, Cardelli P, Ceci F, Paradiso $M$, et al.: Lipoprotein(a) serum levels in patients affected by chronic obstructive pulmonary disease. Atherosclerosis. 1999;147:249-252. doi: 10.1016/S00219150(99)00192-6.

3. Boschetto P., Beghé B., Fabbri L., Ceconi C.: Link between chronic obstructive pulmonary disease and coronary artery disease: implication for clinical practice. Respirology. 2012;17(3):422-31. http://dx.doi. org/10.1111/j.1440-1843.2011.02118.x.

4. Can U, Yerlikaya FH, Yosunkaya S.: Role of oxidative stress and serum lipid levels in stable chronic obstructive pulmonary disease. J Chin Med Assoc. 2015;78:702708. doi: 10.1016/j.jcma.2015.08.004.

5. Cecere L.M., Littman A. J., Slatore C. G. et al.: Obesity and COPD: associated symptoms, health-related quality of life, and medication use. COPD: Journal of Chronic Obstructive Pulmonary Disease, vol. 8, no. 4, pp. 275284, 2011.

6. Clair C., Chiolero A., Faeh D., CornuzJ., Marques-Vidal P., Paccaud F., Mooser V, Waeber G., Vollenweider P.: Dose-dependent positive association between cigarette smoking, abdominal obesity and body fat: crossselectional data from a population-based survey. BMC Public Health. 2011;11:23. doi: 10.1186/1471-2458-11-23.

7. Eisner M.D., Anthonisen N., Coultas D., et al:: An official American Thoracic Society public policy statement: novel risk factors and the global burden of chronic obstructive pulmonary disease. Am J Respir Crit Care Med. 2010;182(5):693-718.

8. Feary J.R., Rodrigues L..C., Smith C.J., Hubbard R.B., Gibson J.E.: Prevalence of major comorbidities in subjects with COPD and incidence of myocardial infarction and stroke: a comprehensive analysis using data from primary care. Thorax. 2010;65(11):956-962.

9. Ferrante $J r . A$. $W$ : Obesity-induced inflammation: a metabolic dialogue in the language of inflammation. Journal of Internal Medicine, vol. 262, no. 4, pp. 408414, 2007.

10. Forey B.A., Thornton A. J., Lee P.N.: Systematic review with meta-analysis of the epidemiological evidence relating smoking to COPD, chronic bronchitis and emphysema. BMC Pulmonary Medicine, vol. 11, no. 1, p. 36, 2011.

11. Franssen F., O'Donnell D., Goossens G., Blaak E., Schols A.: Obesity and the lung: obesity and COPD. Thorax, vol. 63, no. 12, pp. 1110-1117, 2008.

12. Fuller-Thomson E.F., Howden K.E.N., Fuller-Thomson L.R, Agbeyaka S.: A Strong Graded Relationship between Level of Obesity and COPD: Findings from a National Population-Based Study of Lifelong Nonsmokers. Journal of Obesity, vol. 2018, Article ID 6149263, 9 pages, 2018. https://doi.org/10.1155/2018/6149263
13. Global Strategy for the Diagnosis, Management and Prevention of COPD. [Accessed March 9, 2017]. Available from: http:/goldcopd.org/wp-content/ uploads/2016/12/wms-GOLD-2017-Pocket-Guide.pdf.

14. Gunay S, Sariaydin M, Acay A.: New Predictor of Atherosclerosis in Subjects With COPD: Atherogenic Indices. Respir Care. 2016;61:1481-1487. doi: 10.4187/ respcare. 04796 .

15. Hanson C., Rutten E.P., Wouters E.F.M., Rennard S.: Influence of diet and obesity on COPD development and outcomes. Int J Chron Obstruct Pulmon Dis 2014;9:723733. doi: $10.2147 /$ COPD.S50111

16. Jurczak I., Jurczak K.: Chronic obstructive pulmonary disease as a risk factor for coronary heart disease. Pol Merkur Lekarski. 2015;38(223):39-41.

17. Kim J.H., Shim K.W., Yoon Y.S., Lee S.Y., Kim S.S., Oh S.W.: Cigarette smoking increases abdominal and visceral obesity but not overall fatness: an observational study. PLoS One. 2012;7(9):e45815. doi: 10.1371/journal. pone.0045815.

18. Küpeli E., Ulubay G., Ulasli S., Sahin T., Erayman Z., Gürsoy A.: Metabolic Syndrome is associated with increased risk of acute exacerbation of COPD: a preliminary study. Endocr Jour. 2010;38(1):76-82. http://dx.doi.org/10.1007/s12020-010-9351-3 .

19. Kyle U.G., Bosaeus I., De Lorenzo A.D., Deurenberg P., Elia M., Gómez J.M., Heitmann B.L., Kent-Smith L, Melchior J.C., Pirlich M., Scharfetter H., Schols A.M., Pichard C.: Bioelectrical impedance analysis-part I: review of principles and methods. Clinical Nutrition. 23 (5): 1226-43. doi:10.1016/j.clnu.2004.06.004. PMID 15380917.

20. Liu Y., Ma Z., Zhao C. et al.: HIF-1 $\alpha$ and HIF- $2 \alpha$ are critically involved in hypoxia-induced lipid accumulation in hepatocytes through reducing PGC$1 \alpha$-mediated fatty acid $\beta$-oxidation. Toxicology Letters, vol. 226, no. 2, pp. 117-123, 2014.

21. Lozano R., Naghavi M., Foreman K., et al.: Global and regional mortality from 235 causes of death for 20 age groups in 1990 and 2010: a systematic analysis for the Global Burden of Disease Study 2010. Lancet. 2012;380 (9859):2095-2128.

22. Mannino D.M., Thorn D., Swensen A., Holguin F.: Prevalence and outcomes of diabetes, hypertension and cardiovascular disease in COPD. Eur Respir J. 2008;32(4):962-969.

23. Mroz R., Lisowski P., Tycinska A., Bierla J., Trzeciak P., Minarowski L., Milewski R., Lisowska A., Boros P., Sobkowicz B., Duszewska A., Chyczewska E., Musial W., MacNee W.: Anti-inflammatory effects of atorvastatin treatment in chronic obstructive pulmonary disease. Physiol Pharmacol. 2015;66(1):111-28.

24. Park S.K, Larson J.L.: Metabolic syndrome and associated factors in people with chronic obstructive pulmonary disease. West J Nurs Res. 2013 Nov 29;

25. Reed R., Iacono A., DeFilippis A., Eberlein M., Girgis $R$., Jones S.: Advanced chronic obstructive pulmonary disease is associated with high levels of high-density lipoprotein cholesterol. Heart Lung Transplant. 
2011;30(6):674-8. healun.2010.12.010 .

http://dx.doi.org/10.1016/j.

26. Tanni S., Zamuner A., Schelini K., Coelho L., Caram L., Vale S., Ferrari R., Godoy I., Paiva S., Godoy I.: Triglycerides are associated with five-year mortality in COPD patients. European Respiratory Journal. 2012. 40:P522.

27. Van der Toorn M., Smit-de Vries M.P., Slebos D.J., et al.: Cigarette smoke irreversibly modifies glutathione in airway epithelial cells. Am J Physiol Lung Cell Mol Physiol. 2007;293(5):L1156-L1162.

28. Van der Toorn M., Rezayat D., Kauffman H.F., et al.: Lipid-soluble components in cigarette smoke induce mitochondrial production of reactive oxygen species in lung epithelial cells. Am J Physiol Lung Cell Mol Physiol. 2009;297(1):L109-L114.

29. Wang Z., Wang D., Wang Y.: Cigarette Smoking and Adipose Tissue: the Emerging Role in Progression of Atherosclerosis. Mediators Inflamm. 2017;2017:3102737. doi: 10.1155/2017/3102737.

30. WHO: Nutrition, Physical Activity and Obesity Slovakia. https://www.euro.who.int/_data/assets/pdf file/0018/243324/Slovakia-WHO-Country-Profile.pdf
31. WHO: Obesity and overweight. 2020. https://www. who.int/news-room/fact-sheets/detail/obesity-andoverweight.

32. WolfR.N., Grundy S.M.: Influence of weight reduction on plasma lipoproteins in obese patients. Arteriosclerosis. 1983. 3:160-169.

33. Zafirova-Ivanovska B., Stojkovikj J., Dokikj D., Anastasova S., Debresliovska A., Zejnel S, Stojkovikj D.: The Level of Cholesterol in COPD Patients with Severe and Very Severe Stage of the Disease. Open Access Maced J Med Sci. 2016. 15;4(2): 277-282. doi: 10.3889/ oamjms.2016.063.

34. Xuan L., Han F., Gong L., Lv Y., Wan Z., Liu H., Zhang D., Jia Y., Yang S., Ren L., Liu L.: Association between chronic obstructive pulmonary disease and serum lipid levels: a meta-analysis. Lipid Health Dis. 2018. 21;17(1)263. doi: 10.1186/s12944-018-0904-4.

Received: 30.06 .2021

Accepted: 26.07.2021

Published online first: 29.07.2021 